\title{
The association between deprivation levels, attendance rate and triage category of children attending a children's accident and emergency department
}

\author{
T F Beattie, D R Gorman, J J Walker
}

\begin{abstract}
Objective-To determine the relation between deprivation category, triage score and accident and emergency (A\&E) attendance for children under the age of 13 . Design-Retrospective study of all children attending an $A \& E$ department over one year.

Setting-A paediatric teaching hospital in Edinburgh.

Subjects-All children attending the $A \& E$ department who had a postcode and a triage score documented on attendance. The postcode was used to determine the deprivation category and the triage scored the severity of illness or injury.

Main outcome measure-The relation between deprivation category, triage score and frequency of attendance.

Results-There is a trend towards increased attendance in all triage categories for deprivation categories 6 and 7 .

Conclusions-Attendance at $\mathrm{A} \& \mathrm{E}$ is not only related to severity of injury but also to deprivation category. The reason why people from disadvantaged areas attend more frequently needs further evaluation. (Emerg Med f 2001;18:110-111)
\end{abstract}

Keywords: triage category; deprivation category; child

Accident and emergency (A\&E) departments nationally are experiencing a year on year rise in workload. The Royal Hospital for Sick Children in Edinburgh (RHSCE) has experienced an increase in attendances from 20200 in $1992 / 3$, to 29093 in 1997/8 (an increase of $44 \%$ ). There are no clear reasons why this workload is increasing either locally or nationally. Recently the issue of deprivation ${ }^{1}$ and attendance at $\mathrm{A} \& \mathrm{E}$ has been reported, with factors such as deprivation itself and distance from hospital ${ }^{2}$ both being implicated in the rate of attendance. None of these studies have dealt specifically with the paediatric population.

Hull et al have highlighted the need for robust markers of variation in need to be developed. ${ }^{3}$ One such marker could be the triage category of patients presenting to $A \& E$ and the purpose of this study is to investigate whether there are variations in the attendance pattern for children from different deprivation groupings by triage category.
Methods and results

We examined retrospectively all attendances at the RHSCE from 1 April 1996 to 31 March 1997. Triage categories were changed during the next 12 months to reflect National Triage criteria, making a full year comparison difficult. The RHSCE is the only paediatric A\&E department for Edinburgh City, East Lothian and Midlothian. The department sees and treats all paediatric emergencies for children aged under 13 from these areas. All attendances were coded on attendance (that is, post code) and subsequently linked to both the Carstairs Deprivation Category (DEPCAT) (based on the 1991 census) for deprivation and triage category. ${ }^{4}$ The triage category is an objective score allocated on arrival by an experienced registered sick children's nurse for each child attending the A\&E department. One of four categories could be allocated on a range from 1 to $4-1$ is the most severe and requires urgent and immediate resuscitation: 4 is the least severe and treatment could be delayed in these patients. Indeed many could be seen in primary care.

Patients were grouped according to allocated triage category and deprivation score. The proportion of the relevant population represented by each group was calculated. The standard error of that proportion was then computed. Population and sample sizes were sufficiently large to permit use of the normal approximation to the binomial; that is - to treat the observed proportion as a mean value of a normally distributed continuous variable. ${ }^{5}$ The computed standard error was used to derive $99 \%$ confidence intervals for the proportion of the population represented in each triage/ DEPCAT category.

Over the 12 months studied there were 27965 patients registered as attending $\mathrm{A} \& \mathrm{E}$ for the first time - that is, true "first attenders". Of these 26325 (94\%) had reliable triage categories allocated and documented. These form the basis for this study.

Table 1 shows the attendances in each triage category and deprivation score, with upper and lower 99\% confidence intervals presented for the estimated proportion of the relevant population in each cell. Note that "population" in this study refers to the total number of children aged under 13 in the community served by the RHSCE. The data suggest a trend down the rows with a proportion of attendance in the deprivation category 6/7 slightly greater than those for less deprived DEPCAT groups. This 
Table 1 Attendance in each triage category and deprivation score

\begin{tabular}{|c|c|c|c|c|c|c|c|c|c|}
\hline$D E P C A T$ & Population & $\begin{array}{l}\text { Number in } \\
\text { triage } \\
\text { category } 1\end{array}$ & $\begin{array}{l}\text { Triage category } 1 \text { : } \\
\text { proportion of } \\
\text { population }\end{array}$ & $\begin{array}{l}\text { Number in } \\
\text { triage } \\
\text { category } 2\end{array}$ & $\begin{array}{l}\text { Triage category } 2 \text { : } \\
\text { proportion of } \\
\text { population }\end{array}$ & $\begin{array}{l}\text { Number in } \\
\text { triage } \\
\text { category } 3\end{array}$ & $\begin{array}{l}\text { Triage category } 3: \\
\text { proportion of } \\
\text { population }\end{array}$ & $\begin{array}{l}\text { Number in } \\
\text { triage } \\
\text { category } 4\end{array}$ & $\begin{array}{l}\text { Triage category } 4 \text { : } \\
\text { proportion of } \\
\text { population }\end{array}$ \\
\hline 1 and 2 & 27777 & 21 & $0.0003-0.001$ & 185 & $0.005-0.008$ & 1105 & $0.037-0.043$ & 4265 & $0.148-0.159$ \\
\hline 3,4 and 5 & 68608 & 102 & $0.001-0.002$ & 593 & $0.008-0.010$ & 3428 & $0.048-0.052$ & 13743 & $0.196-0.204$ \\
\hline 6 and 7 & 6570 & 26 & $0.002-0.006$ & 84 & $0.009-0.016$ & 549 & $0.075-0.092$ & 2224 & $0.323-0.354$ \\
\hline All & 102955 & 149 & $0.001-0.002$ & 862 & $0.008-0.009$ & 5082 & $0.048-0.051$ & 20232 & $0.193-0.200$ \\
\hline
\end{tabular}

Triage categories: $1=$ immediate resuscitation required, $2=$ urgent medical attention required, $3=$ significant illness or injury requiring medical care and $4=$ minor illness or injury potentially amenable to treatment in primary care. DEPCAT = Carstairs Deprivation Category.

trend is particularly evident in triage categories 3 and 4 .

\section{Discussion}

Previous studies have concentrated on attendances for either adult patients or for both adult and paediatric populations. ${ }^{126}$ Children have different pathology, different needs and usually do not present unless brought by parents or guardians. There is therefore a need to examine the patterns of attendance in the paediatric population separately from a combined or adult situation.

These results clearly demonstrate a relation between $\mathrm{A} \& \mathrm{E}$ department use and deprivation category for all assessed triage categories. This is most noticeable at the severe end of the spectrum, the attendance rate under triage 1 from DEPCAT 6/7 being about five times higher than in DEPCAT $1 / 2$. For minor illness/injury (triage 4 ), the corresponding ratio is about two (though absolute numbers of attendances are of course much higher). It is, however, not clear whether this reflects the true incidence of illness or injury in these categories: whether it is a manifestation of different ways of coping with injury or illness: or whether it is a combination of both.

It is also clear that in Lothian the actual numbers of residents living in the high deprivation areas-that is, areas 6 and 7, are relatively small compared with the numbers of people who live in more affluent areas. Targeting deprived areas with facilities to treat minor injuries more locally or with health education messages will not achieve a significant reduction in overall A\&E attendances locally. Efforts to reduce attendances from these areas must clearly tackle inappropriate attendances from all DEPCAT categories. How this can be achieved needs further elucidation.

Caution will be needed in extrapolating these findings to other areas. The use of the
Carstairs criteria needs to be considered as other scales and parameters have been used in other studies. ${ }^{6}$ Those with different distributions of deprivation may need a variety of approaches. Further studies are needed to determine the community based incidence of injury and illness and how this relates to access to minor injury and GP services at a community level; GP and community management of illness and injury; and self management of the problems and how this relates to education, knowledge and social expectations.

This study has demonstrated that deprivation is an important factor in $\mathrm{A} \& \mathrm{E}$ attendances, but greater emphasis needs to be placed on identifying why so many children attend A\&E departments for minor and moderate injury and illness. It also demonstrates that there is a small but significant increase in the level of serious illness in the highly deprived group (DEPCATs 6 and 7) that also requires further elucidation.

Contributors

TFB will act as guarantor for the study. TFB and DRG conceived the project. TFB arranged for hospital data to be collected and analysed; DRG arranged for the community population details to be derived; JJW provided statistical advice. TFB, DRG and JJW all contributed to writing the paper and its final preparation.

Funding: none.

Conflicts of interest: none.

1 Hull SA, Jones IR, Moser K. Factors influencing the attendance rate at accident and emergency departments in East London: the contributions of practice organization, population characteristics and distance. F Health Serv Res Policy 1997;2:6-13.

2 Campbell J. Relation of rates of self referral to A\&E departments to deprivation. Distance from department and deprivation are both important in explaining variations in rates [letter; comment]. BMF 1998;317:538.

3 Hull S, Jones IR, Moser K. Relation of rates of self referral to $\mathrm{A} \& \mathrm{E}$ departments to deprivation. Robust markers are needed of variations in case mix among practices [letter; comment]. BMf 1998;317:538

4 Carstairs V, Morris R. Deprivation and health in Scotland. Aberdeen: Aberdeen University Press, 1991

5 Ott R. An introduction to statistical methods and data analysis. 4th ed. Belmont, CA: Duxbury Press, 1993.

6 Carlisle R, et al. Relation of out of hours activity by general practice and Accident and Emergency services in
Nottingham-a longitudinal study. BMf 1998;316:520-3. 